5. Jaurigue M.M, Cappell M.S. (2014). Therapy for alcoholic liver disease. World J Gastroenterol. 20(9): 2143-58.

6. Mann R.E, Smart R.G, Govoni R. (2003). The Epidemiology of Alcoholic Liver Disease. Alcohol Research \& Health., 27(3): 209-219.
7. Schafer A.L, Shoback D.M. (2016). Hypocalcemia: Diagnosis and Treatment. South Dartmouth (MA): MDText.com, Inc. 2000-

8. Chiba T, Okimura Y, Inatome T, et al. (1987). Hypocalcemic crisis in alcoholic fatty liver: transient hypoparathyroidism due to magnesium deficiency. Am J Gastroenterol., 82(10):1084-7.

\title{
BƯớC ĐÂU ĐÁNH GIÁ KẾT QUẢ CỦA KỸ THUÂTT CẮT U THẦN KINH NộI TIẾT ĐƯờ'NG TIÊU HOÁ QUA NộI SOI ỐNG MỀM
}

\section{TÓM TẮT}

Nghiên cứu thu thập 25 bệnh nhân với 26 khối u có chẩn đoán u thần kinh nội tiết đường tiêu hóa qua kết quả mô bệnh học từ 01/01/2016 đến 31/07/2020. Chủ yếu các khối ở trưc tràng $(84,6 \%)$, xuất phát tai lớp dưới niêm mạc $(61,1 \%)$ và có kích thước dưới $2 \mathrm{~cm}$ $(100 \%)$. Tất cả các khối u có ranh giới rõ và xung quanh không thấy có hạch. Các bệnh nhân được cắt khối u bằng snare có tiêm phồng adrenalin 1/10000 $(73,1 \%)$ hoắc theo phương pháp cắt polyp không tiêm adrenalin $(26,9 \%)$. Tỷ lê căt hết toàn bô các khối u đạt $100 \%$. Mức độ thực hiện kỹ thuật đạt kết quả tốt là 24 bênh nhân $(96,0 \%)$, có 1 bênh nhân không đạt $(4,0 \%)$ do sau căt xảy ra tai biển thủng trực tràng phải phẫu thuật nội soi qua ống hậu môn để khâu đóng. Tất cả các khối u đều có kết quả mô bệnh học của NET điển hình và có $8 / 25$ bênh nhân có kết quả hóa mô miến dịch đối với một số maker CD56, Chromogranin, CK10, HE, Ki67, Neuron-specific enolase, synaptiphysin. Nghiên cứu bước đầu cho thấy kỹ thuật cắt u qua nội soi ống mềm là kỹ thuật có hiệu quả và an toàn trong điều trị u thần kinh nội tiết đường tiêu hoá.

Từ khoá: u thần kinh nội tiết, carcinoid, cắt u qua nội soi, cắt hớt niêm mạc qua nội soi

\section{SUMMARY}

PRELIMINARY RESULT OF

\section{NEUROENDOCRINE TUMOUR RESECTION} USING FLEXIBLE ENDOSCOPY

From January 1, 2016 to July 31, 2020, our study collected 25 patients which had 26 tumors with a histological diagnosis of gastrointestinal neuroendocrine tumors (NET). Most tumors located in the rectum $(84.6 \%)$, originated from the submucosa

\footnotetext{
${ }^{1}$ Viện Nghiên cứu và đào tạo Tiêu hóa, gan mật,

2Trường Đai hoc Y Hà Nôi

${ }^{3}$ Bệnh viện Đại học Y Hà Nội,

${ }^{4}$ Trường Đại học Y Dược, Đại học Quốc gia Hà Nội

Chiu trách nhiệm chính: Đào Việt Hằng

Email: hangdao.fsh@gmail.com

Ngày nhận bài: 16.11.2020

Ngày phản biện khoa học: 29.12.2020

Ngày duyệt bài: 7.01.2021
}

\section{Đào Việt Hằng 1,2,3, Trần Ngọc Minh², Trần Thị Thu Trang ${ }^{1,4}$, Đào Văn Long ${ }^{1,2}$}

$(61.1 \%)$ and were less than $2 \mathrm{~cm}(100 \%)$. All tumors had clear delineation and had no lymph nodes. The tumors were removed by snare resection assisted by submucosal injections of $1 / 10000$ adrenaline $(73.1 \%)$ or by non-assisted snare resection $(26.9 \%)$. The rate of complete removal was $100 \%$. 24 patients $(96.0 \%)$ achieved good results, 1 patient $(4.0 \%)$ had rectal perforation after the intervention and had to undergo laparoscopic surgery for closure. On histopathology, all tumors had typical characteristics of NET. On immunohistochemistry, $8 / 25$ patients showed expressions of several CD56 makers, Chromogranin, CK10, HE, Ki67, Neuron-specific enolase, synaptophysin. Our preliminary study showed that endoscopic resection was effective and safe in the treatment of neuroendocrine tumors

Keywords: Neuroendocrine tumors, NET, carcinoid, endoscopic resection, endoscopic mucosal resection, EMR

\section{I. Đă̆T VẤN ĐỀ}

U thần kinh nội tiết (neuroendocrine tumors NETs) là khối u có nguồn gốc từ các tế bào thần kinh nội tiết, hiếm gặp và có đặc điểm lâm sàng đa dạng, không điển hình. Tỷ lệ mắc trên thế giới được ghi nhận tăng dần trong những năm gần đây dao động từ 1,09/100000 (năm 1973), $5,25 / 100000$ (năm 2004) và 6,98/100000 (năm 2012) [1]. NET có thể xuất hiện ở nhiều cơ quan trên cơ thể như đường tiêu hoá, buồng trứng, phổi, tinh hoàn, thanh quản... Trong đó, đường tiêu hoá, cụ thể là ruột non và trực tràng là vị trí thường gặp nhất. Các khối u này có thể được phát hiện tình cờ trong quá trình nội soi sàng lọc hoặc khi người bệnh có một số triệu chứng như chảy máu, tiêu chảy.

Theo khuyến cáo của một số Hiệp hội ung thư trên thế giới, nguyên tắc quản lý chung đối với NET là xác định vị trí, giai đoạn, đặc điểm mô bênh học, độ biệt hoá, từ đó cân nhắc lựa chọn điêu trị phương pháp tại chỗ (cắt qua nội soi, phẫu thuật, nút mạch, đốt sóng cao tân) hoặc sứ dụng các liệu pháp toàn thân (hoá trị liệu, miễn 
dịch) và kiểm soát hội chứng thần kinh nội tiết $[2,3]$.

Theo các báo cáo, các khối u khi phát hiện đa phần có kích thước $<1 \mathrm{~cm}$, ít di căn tại thời điểm chẩn đoán và bệnh nhân thường không có triệu chứng [4]. Phân loại về mô bệnh học của Tổ chức y tế thế giới (WHO) năm 2017 cũng nhấn mạnh việc phân biệt rõ ba khái niệm u thần kinh nội tiết (NET), ung thư thần kinh nội tiết (neuroendocrine carcinoma - NEC) và thể hỗn hợp (mixed neuroendocrine-non-neuroendocrine neoplasm - MiNEN) [5]. Những trường hợp được xác định là NET đường tiêu hóa với kích thước nhỏ, không có xâm lấn có thể áp dụng phương pháp điêu trị cắt khối u qua nội soi hoặc phẫu thuật xâm lấn tối thiểu được ưu tiên. Chỉ định và kĩ thuật nội soi lựa chọn phụ thuộc vào vị trí xuất phát và kích thước của khối u [2]. Một số báo cáo trên thế giới sử dụng kỹ thuật cắt hớt niêm mạc (EMR-endoscopic mucosal resection) hoặc cắt tách dưới niêm mạc (ESD - endoscopic submucosal dissection) cho thấy tỷ lệ cắt bỏ hoàn toàn cao khoảng $90 \%[2,6]$. Tại Việt Nam, các kỹ thuật này cũng đã được áp dụng để cắt các polyp lớn, các tổn thương u có nguy cơ ác tính cao hoặc ung thư sớm đường tiêu hoá, tuy nhiên chưa có dữ liêu liên quan đến kết quả thành công cũng như tai biến về mặt kỹ thuật đối với NET đường tiêu hóa. Vì vậy chúng tôi tiển hành nghiên cứu này nhằm mục tiêu đánh giá bước đầu kết quả kỹ thuât cắt u thần kinh nội tiết đường tiêu hóa qua nội soi ống mềm.

\section{II. ĐỐI TƯợNG VÀ PHƯƠNG PHÁP NGHIÊN CứU}

Đối tượng: Nghiên cứu hồi cứu mô tả 25 bệnh nhân được chẩn đoán là u thần kinh nội tiết đường tiêu hóa bằng mô bệnh học sau cắt u qua nội soi, từ 01/01/2016 đến 31/07/2020.

Quy trình nghiên cứu: Dựa vào hồ sơ bệnh án lưu trữ tại phòng khám, nhóm nghiên cứu thiết kế mẫu bệnh án nghiên cứu thống nhất bao gồm các thông tin về nhân khẩu học, kết quả siêu âm nội soi, quá trình cắt u qua nội soi ống mềm, mô bệnh học và hoá mô miễn dịch (nếu có).

Quá trình cắt khối u qua nội soi:

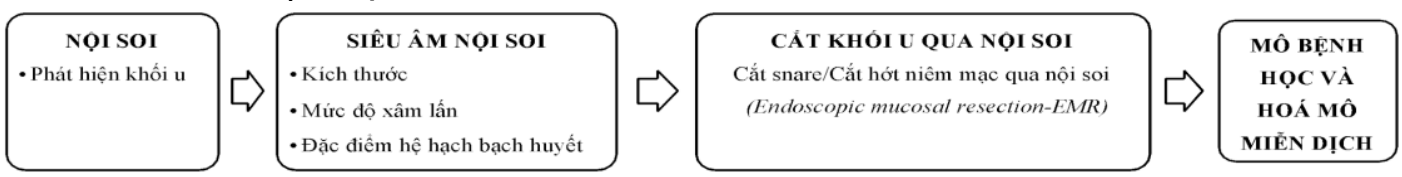

Hình 1. Quy trinh cắt khôi u qua nội soi

Các tiêu chuẩn đánh giá: Đánh giá về mức độ thực hiện kỹ thuật cắt khối u qua nội soi:

- Kết quả tốt: lấy được toàn bộ khối và không xảy ra biến chứng trong quá trình làm thủ thuật.

- Trung bình: lấy được hết toàn bô khối nhưng xảy ra biến chứng trong quá trình làm thủ thuật và xử lý được can thiệp, không phải nằm viện.

- Không đạt: không lấy được hết khối hoặc sau can thiệp bệnh nhân gặp biến chứng lớn cần phải nhập viện.

Đánh giá lấy được hết tổn thương dựa trên kết quả mô bệnh học (diện cắt dưới và diện cắt bên đều không còn $\mathrm{u}$ ).

Đánh giá biến chứng: ghi nhận biến chứng trong và ngay sau quá trình làm thủ thuật cần can thiệp khi bệnh nhân được theo dõi tại đơn vị và trong vòng 1 tuần sau đó.

Xử lý số liệu: Các số liệu được nhập và xử lý theo phần mềm SPSS. Các biến định tính được biểu diễn dưới dạng số đếm và tỷ lê phần trăm. Các biến liên tục được biểu diễn dưới dạng trung bình (độ lệch chuẩn).

Đạo đức nghiên cứu: Nghiên cứu không thu thập các thông tin nhạy cảm. Các số liệu có thể xác định được danh tính của đối tượng tham gia nghiên cứu sẽ bị loại bỏ khi phân tích số liệu và không được đưa vào bất kì một công bố nào liên quan tới nghiên cứu. Do đây là nghiên cứu hồi cứu trên số liệu thu thập trong thực hành thường quy của đớn vị y tế, chúng tôi không tiến hành lấy chấp thuận tham gia nghiên cứu. Hội đồng Khoa học-kỹ thuật của Viện Nghiên cứu và Đào tạo Tiêu hóa, Gan mật đã thông qua đề cương nghiên cứu về mặt khoa học. Trước khi thu thập số liệu, phòng khám Hoàng Long đồng ý cho nhóm nghiên cứu được truy cập vào số liệu lâm sàng hồi cứu.

\section{KẾT QUẢ NGHIÊN CỨU}

3.1. Đặc điểm nhóm bệnh nhân nghiên cứu. Từ 01/01/2016 đến 31/07/2020, nghiên cứu thu thập được 25 bệnh nhân: tuổi trung bình $50,1 \pm 11,4$ năm (min-max 31-71), tỷ lệ nữ/nam là 1,08 . Tổng cộng có 26 khối u được phát hiện, chỉ có một bệnh nhân có 2 khối u. Phần lớn các khối u ở trực tràng $(84,6 \%)$ và có kích thước dưới $1 \mathrm{~cm}(69,2 \%)$.

Bảng 1. Đặc điểm chung của bệnh nhân Đăc điểm Theo bệnh nhân ( $N=25)$ 


\begin{tabular}{|c|c|}
\hline Giới tính: Nữ/nam & $13 / 12(1,08)$ \\
\hline Tuổi (mean $\pm S D$ (min-max)) & $50,1 \pm 11,4$ \\
& $(31-71)$ \\
\hline Số lượng khối u: 1 khối u & $24(96,0)$ \\
2 khối u & $1(4,0)$ \\
\hline \multicolumn{2}{|c|}{ Theo khối u (N=26) } \\
\hline Vi trí khối u: Trực tràng & $22(84,6)$ \\
Hành tá tràng & $3(11,5)$ \\
Hồi tràng & $1(3,9)$ \\
\hline Kích thước: <1cm & $18(69,2)$ \\
$1-2 \mathrm{~cm}$ & $8(30,8)$ \\
\hline
\end{tabular}

3.2. Đặc điểm siêu âm nội soi. Nghiên cứu ghi nhận 17 bệnh nhân (18 khối u) có kết quả siêu âm nội soi. Tất cả các khối u có ranh giới rõ và xung quanh khối u không thấy có hạch. Bảng 2 mô tả đặc điểm trên siêu âm nội soi của 18 khối u.

Bảng 2. Đặc điểm siêu ầm nội soi

\begin{tabular}{|l|l|}
\hline Đặc điểm siêu âm nội soi & $\begin{array}{l}\text { Kết quả } \\
(\mathbf{N}=18)\end{array}$ \\
\hline
\end{tabular}

\begin{tabular}{|c|c|}
\hline Vị trí xuất phát của khối u & \\
Dưới lớp niêm mạc & $11(61,1)$ \\
Lớp niêm mạc & $7(38,9)$ \\
\hline Đặc điếm Echo: Thưa âm & $16(88,9)$ \\
Giảm âm & $2(11,1)$ \\
\hline Độ đồng nhất: Đồng nhâ̂t & $16(88,9)$ \\
Không đồng nhất & $2(11,1)$ \\
\hline
\end{tabular}

\subsection{Kết quả cắt khối u qua nôi soì}

Tất cả các bệnh nhân được cắt u qua nội soi ống mềm sử dụng hot snare có hoặc không tiêm adrenalin. Chủ yếu các bệnh nhân trong nghiên cứu được cắt bằng phương pháp tiêm nhấc bằng adrenalin 1/10000, sau đó cắt bằng hot snare $(73,1 \%)$ (Bảng 3). Tỷ lệ cắt hết toàn bộ các khối u đạt $100 \%$. Mức độ thực hiện kỹ thuật đạt kết quả tốt là 24 bệnh nhân $(96,0 \%)$, chỉ có 1 bệnh nhân không đạt $(4,0 \%)$ do sau cắt xảy ra tai biến thủng trực tràng phải phẫu thuật nội soi qua ống hậu môn để khâu đóng (Hình 2).

\section{Bảng 3. Kết quả cắt u thần kinh nội tiết}

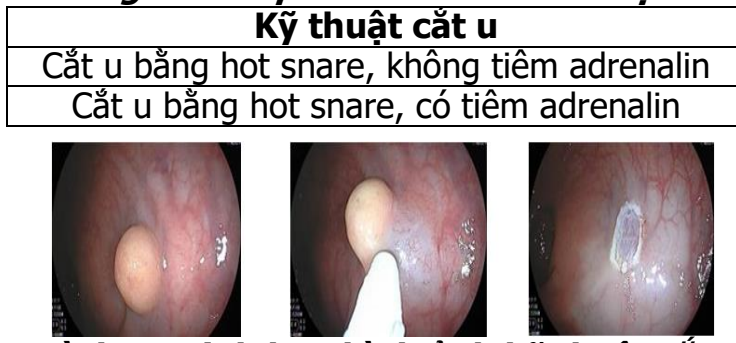

Hình 1. Minh họ hình ảnh kỹ thuật cắt u thần kinh nội tiêt qua nội soi

Sau khi cắt $u$, chúng tôi theo dõi các bênh nhân thông qua phỏng vấn bằng điện thoại. Kết quả liên lạc được $18 / 25$ bệnh nhẩn với trung bình thời gian theo dõi là $25,3 \pm 15,5$ tháng (1 tháng-55 tháng).

Tất cả các bệnh nhân không có triệu chứng

\begin{tabular}{|c|c|}
\hline $\mathbf{N}(\%)$ & Kích thước trung bình (cm) \\
\hline $7(26,9)$ & $1,02 \pm 0,50, \min -\max 0,5-1,8$ \\
\hline $19(73,1)$ & $0,79 \pm 0,20, \min -\max 0,5-1,2$ \\
\hline
\end{tabular}

lâm sàng liên quan đến hội chứng thần kinh nội tiết. Nghiên cứu ghi nhận có 1 bệnh nhân xuất hiện u mới ở vị trí khác sau 34 tháng và đã được cắt lần 2, tuy nhiên không ghi nhận được kết quả mô bệnh học của khối u cắt lần 2.

3.5. Kết quả mô bệnh học và hoá mô miến dịch. Tất cả các khối u đều có kết quả mô bệnh học của NET điển hình, không ghi nhận trường hợp nào là NEC hoặc MiNET. Có 8/25 bệnh nhân có kết quả hóa mô miễn dịch đối với một số maker CD56, Chromogranin A (CgA), CK10, HE, Ki67, Neuron-specific enolase (NSE), synaptophysin (Hình 3,4)
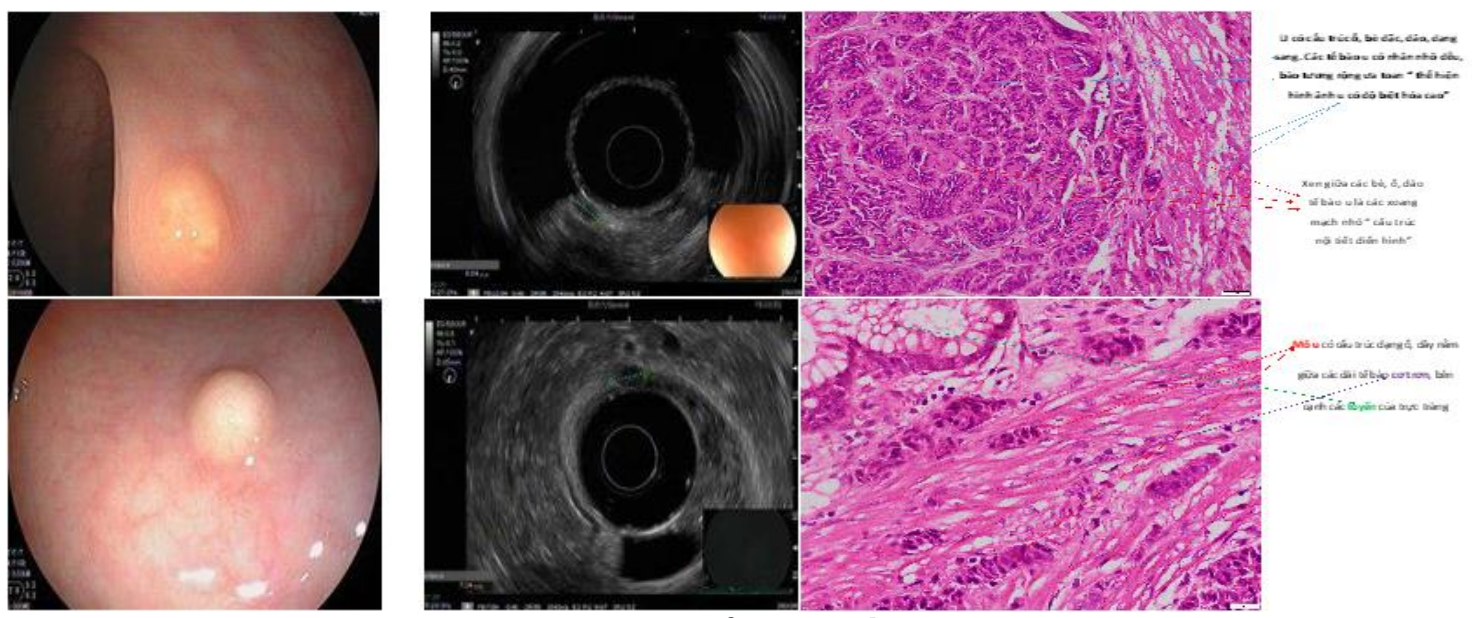

(a) NET ở trực tràng 


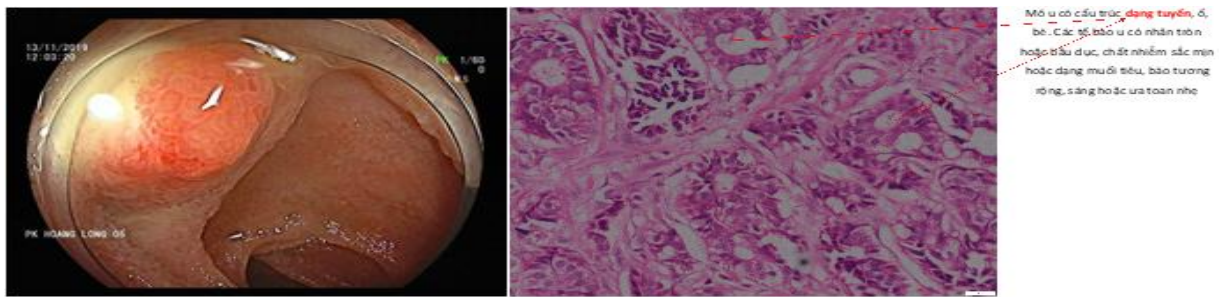

(b) NET ở hồi tràng

Hinh 2. Hình ảnh giải phẫu bệnh điển hình của NET

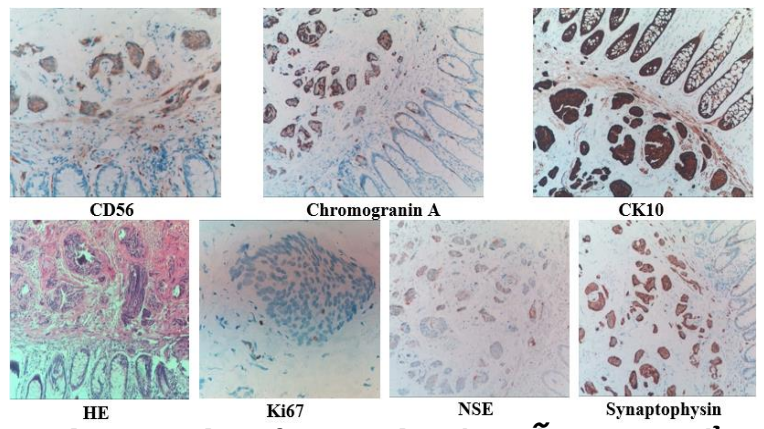

Hình 3. Hình ảnh hoá mô miễn dịch điển hinh NET

\section{BÀN LUÂNN}

Đặc điểm chung. Chúng tôi ghi nhận được 25 bệnh nhân với 26 khối u. Các bênh nhẩn trong nghiên cứu của chúng tôi không có các triệu chứng điển hình và đều phát hiện tình cờ trong quá trình nội soi. Các triệu chứng bệnh nhân có NET có thể gặp bao gồm: đau bụng, giảm cân, nôn, chảy máu đường tiêu hoá, táo bón, tắc ruột, chủ yếu là tiêu chảy và nóng đỏ da (cutaneousc flusing). Các triệu chứng điển hình này chỉ xảy ra ở khoảng $30-40 \%$ bênh nhân [4]. Bên cạnh đó, NET ở đường tiêu hóa có đặc điểm phát triển từ các tế bào thần kinh nội tiết trong đường tiêu hóa, xâm lấn vào lớp cơ niêm, và lớp dưới niêm mạc ngay cả ở giai đoạn đầu. Bởi vậy, trên hình ảnh nội soi, tổn thương là các khối u dưới niêm mạc đường tiêu hóa. Tuy nhiên rất nhiều khối u không tiết hormon hoặc ở giai đoạn sớm, bệnh nhân không có triệu chứng hoặc có các triệu chứng không điển hình nên chỉ được phát hiện tình cờ trong quá trình nội soi đường tiêu hóa [7].

Nghiên cứu ghi nhận phần lớn các khối u phát hiện ở trực tràng $(84,6 \%)$, số còn lại thây ở hành tá tràng và hồi tràng. Kêt quả này khác với một số báo cáo trên thế giới với cỡ mẫu lớn hơn và được theo dõi trong nhiều năm cho thây tỷ lệ phân bố NET ở trực tràng chỉ chiếm khoảng $20 \%$ các khối u phát hiện ở đường tiêu hoá $[8,9]$. Nghiên cứu của Jetmore chỉ ra rằng vị trí NET thường gặp nhất là ruột thừa (38\%), tiếp là ruột non $(30 \%)$, trực tràng $(19 \%)$, đại tràng $(9 \%)$, da dày $(3 \%)$, thực quản (1\%) [9]. Một dữ liệu khác cho thấy ruột non là vị trí hay gặp nhất $(45 \%)$, sau đó đến trực tràng $(20 \%)$, ruột thừa $(16 \%)$, đại tràng $(11 \%)$ và da dày $(7 \%)[8]$. Sự khác biệt này là do các kỹ thuật thăm dò ruột non còn tương đối hạn chế tại Việt Nam và chỉ được thực hiện ở các cơ sở y tế iớn. Bên cạnh đó, đơn vị của chúng tôi chủ yếu thăm khám chuyên khoa nội tiêu hóa và các mẫu bệnh phẩm hồi cứu là cắt qua nội soi, khác so với các nghiên cứu tại các bệnh viện với các mẫu bệnh phẩm cắt u thu thâp được cả từ trong phẫu thuật. Bởi vậy, cần các nghiên cứu đa trung tâm với cỡ mẩu lớn hơn để ước tính chính xác hơn tần suất NET tại các vị trí trên đường tiêu hoá đối với quần thể người Việt Nam.

Đặc điểm siêu âm nội soi. Theo Hiệp hội u thần kinh nội tiết, siêu ầm nội soi là phương pháp giúp xác định kích thước, vị trí xuất phát, phân bố mạch máu, mức độ xâm lấn của khối u dưới niêm mạc và đánh giá hạch vùng nếu có. Vị trí xuất phát của khối u có vai trò quan trọng trong việc lựa chọn điều trị. Các khối u xuất phát từ lớp cơ niêm hoặc dưới niêm mạc có thể lựa chọn cắt bỏ qua nội soi, trong khi các khối u xuất phát từ lớp cơ được điêu trị tốt nhất bằng phẫu thuật. Đặc biệt, với các khối $u<2 \mathrm{~cm}$, siêu âm nội soi có thể chẩn đoán chính xác vị trí xuất phát, mức độ xâm lấn nếu có; và một số nghiên cứu đã chỉ ra kỹ thuật này có mối tướng quan tốt đối với cả kết quả nội soi và mô bệnh học [6]. Trong nghiên cứu của chúng tôi, các khối u được đánh giá bằng siêu âm nội soi đều cho thây các đặc điểm ở giai đoạn sớm và chưa có dấu hiệu xẩm lấn, phù hợp với chỉ định cắt u qua nội soi.

Đăcc điểm mô bênh học và hoá mồ miễn dịch. Tất cả các bệnh nhân được được chẩn đoán u thần kinh nội tiết dựa trên kết quả mô bệnh học, trong đó có 8 bệnh nhân được nhuộm hoá mô miễn dịch. Theo phân loại của WHO nằm 2017, NET là các khối u có mức độ biệt hóa cao và sẽ được phân độ thành 3 nhóm G1, G2, G3 dựa vào chỉ số nhân chia và sự bộc lộ Ki-67 [5]. 
Trong nghiên cứu này chúng tôi không ghi nhận trường hợp nào có tế bào ung thư (NEC) hoặc là thể hốn hợp (MiNEN) cần được phối hợp các phương pháp điều trị khác do vậy chỉ định cắt qua nội soi là hợp lý. Tuy nhiên hạn chế trong nghiên cứu này là kết quả mô bệnh học ghi nhận là hồi cứu chỉ xác định các tổn thương sau cắt là NET mà không phân độ thành 3 nhóm. Sự khác biệt trong sử dụng phân loại mô bệnh học để đánh giá tổn thương ở các đơn vị y tế cũng là một trong những rào cản của thực hành lâm sàng, đặc biệt cho các tuyến cơ sở, đòi hỏi cần có những hướng dẫn, đồng thuận hết sức cụ thể từ các hội chuyên ngành khi tiếp cận những bệnh lý khó, hiếm gặp như NET.

Nghiên cứu chỉ ghi nhận 8 bệnh nhân được nhuộm hoá mô miễn dịch. Điều này có thể giải thích do chi phí của xét nghiệm này tương đối cao nên không phải tất cả các bệnh nhân đều có điều kiện thực hiện. Tuy nhiên, trong một số trường hợp, hình ảnh vi thể không đặc hiệu sẽ không xác định được chính xác nguồn gốc tế bào u, trên cùng một tiêu bản có thể gợi ý nhiều chẩn đoán khác nhau, và ngược lại, có nhiều loại tế bào ung thư với nguồn gốc khác nhau nhưng có hình thái khá giống nhau. Khi đó, kỹ thuật này cho phép quan sát được sự hiện diện của kháng nguyên trên tế bào và mồ, nhờ đó có thể đánh giá được các đặc điểm về hình thái học, kiểu hình miễn dịch của tế bào $u$, tiên lượng $u$ lành tính/ác tính. Bởi vậy, trong thực hành lâm sàng nên cân nhắc tư vấn cho bệnh nhân về giá trị của kỹ thuật này trong các trường hợp cần thiết giúp tối ưu hoá chẩn đoán xác định và quản lý u thần kinh nội tiết.

Kết quả kỹ thuật cắt NET đường tiêu hóa qua nội soi ống mềm. Hai yếu tố tiên lượng quan trọng nhất của NET là kích thước và mức độ xâm lấn đến lớp cơ. Cắt khối u qua nội soi được chỉ định cho các khối u nhỏ kích thước $<2 \mathrm{~cm}$, độ biệt hoá cao, không xâm lấn vào lớp cơ, không xâm lấn mạch, nguy cơ di căn thấp ở dạ dày, tá tràng hoặc trực tràng [7]. Trong đó, EMR là kỹ thuật được sự dụng để cắt bỏ các tổn thương phẳng hoặc không cuống có nguồn gốc từ lớp niêm mạc hoặc dưới niêm mạc với kích thước $<2 \mathrm{~cm}$, hoặc cắt từng phần với các tổn thương lớn hớn. Trong khi ESD được sử dụng để cắt nguyên khối các tổn thương lớn hơn (thường $>2 \mathrm{~cm}$ ), phẳng của ống tiêu hóa, nằm ở sâu trong lớp dưới niêm mạc và tỷ lệ cắt bỏ toàn bộ cao. Trong nghiên cứu này, $26,9 \%$ các trường hợp được cắt bằng snare (polypectomy) và $73,1 \%$ sử dụng kỹ thuật $E M R$ và tỷ lệ cắt bỏ toàn bộ là $100 \%$. Các khối u trong nghiên cứu đều có nguồn gốc từ lớp niêm mạc và dưới niêm mạc, không có dấu hiệu xâm lấn qua các lớp hoặc di căn hạch, tất cả đều có kích thước dưới $2 \mathrm{~cm}(\sim 70 \%$ dưới $1 \mathrm{~cm})$ nên hoàn toàn phù hợp với chỉ định cắt qua nội soi. Kết quả trong nghiền cứu của chúng tôi tương tự với các báo cáo khác đã được ghi nhận trên thể giới về hiệu quả của kỹ thuật cắt khối u qua nội soi trong điều trị NET. Các nghiên cứu được tiến hành trên các bệnh nhân có NET ở nhiều vị trí trên đường tiêu hoá (thực quản, da này, tá tràng, trực tràng), kích thước chủ yếu $<2 \mathrm{~cm}$, với tỷ lệ cắt bỏ toàn bộ cao dao động từ 49,5\% - 100\% [6].

Khi so sánh các kỹ thuật cắt qua nội soi cần lưu ý còn phụ thuộc vào vị trí của các khối u [6]. Tại dạ dày, EMR có ưu điểm là đớn giản, thời gian thực hiện ngắn hơn nhưng hạn chế là không đí sâu được và tỷ lệ cắt bỏ toàn bộ thấp hơn ESD. Tuy nhiên, phướng pháp ESD lại cho thấy có thể không tối ưu với các khối u ở hành tá tràng do có nguy cơ biến chứng chảy máu và thủng cao hơn các vị trí khác trong ống tiêu hóa. Tại trực tràng, bằng chứng từ các tổng quan hệ thống và phân tích gộp còn chưa thống nhất. ESD là phương pháp điều trị hiệu quả và an toàn hơn, nhưng nếu EMR được hỗ trợ bởi vòng thắt cao su hoặc "cap" có thể cho kết quả tương đương với ĖSD.

Tỷ lệ biến chứng sau can thiệp nội soi ở bệnh nhân có NET được báo cáo tại các nghiên cứu trên thế giới dao động từ $3-12 \%$, chủ yếu là chảy máu [6]. Kết quả tương tự đã được ghi nhận trong nghiên cứu này với một trường hợp xảy ra biến chứng thủng sau cắt $(4,0 \%)$. Bệnh nhân có khối u cách hậu môn $10 \mathrm{~cm}$, u nằm ở lớp dưới niêm mạc trên siểu âm nội soi, kích thước $0,7 \mathrm{~cm}$ và được làm EMR. Diện chân cắt có một lỗ nhỏ sâu do phần bao xơ quanh nhân khối u có một chân ăn sâu xuống lớp cơ và chạm tới sát lớp thành ngoài bị kéo lên theo khối. Đây cũng là một trường hợp khó do khối có kích thước bé nên đánh giá trên siêu âm nội soi không tiên lượng được khả năng khối có vị trí ăn sâu vào lớp cơ cũng là một yếu tố gây nguy cơ thủng cao hơn. Do đó, trong quá trình thực hiện thủ thuật cũng cần lưu ý đánh giá đầy đủ nhiều yếu tố để tránh các biến chứng sau cắt hoặc có các hướng xử lý kịp thời.

Theo dõi bệnh nhân sau cắt khối u qua nội soi. Chúng tôi có tiến hành theo dõi bệnh nhân và chỉ ghi nhận 1 trường hợp tái phát. Kết quả này cũng tương đồng với các nghiên cứu trên thế giới với tỷ lệ tái phát và di căn thấp (0- 
$3 \%)$. Tuy nhiên, thời gian theo dõi còn chưa có sự thống nhất [6]. Các hướng dẫn hiện nay về quản lý các khối u nội tiết khuyến cáo cần theo dõi, giám sát tình trạng tái phát và di căn của các bệnh nhân sau khi cắt qua nội soi, với thời gian theo dõi phụ thuộc vào vị trí, kích thước, phân loại, mức độ và kết quả cắt $[2,3]$.

\section{KẾT LUÂN}

Trong số các bệnh nhân được chẩn đoán u thần kinh nội tiết qua kết quả mồ bệnh học, chủ yếu các khối ở trực tràng $(84,6 \%)$, xuất phát tại lớp dưới niêm mạc $(61,1 \%)$ và có kích thước dưới $2 \mathrm{~cm}(100 \%)$. Nghiên cứu bước đầu cho thấy kỹ thuật cắt u qua nội soi ống mềm là kỹ thuật có hiệu quả và an toàn trong điều trị u thần kinh nội tiết đường tiêu hoá với tỷ lệ cắt hết toàn bộ các khối u đạt $100 \%$; tỷ lệ biến chứng thủng trong quá trình cắt thấp $(4,0 \%)$.

\section{TÀI LIẸU THAM KHẢO}

1. Yao, J.C., et al., One hundred years after "carcinoid": epidemiology of and prognostic factors for neuroendocrine tumors in 35,825 cases in the United States. J Clin Oncol, 2008. 26(18): p. 3063-72.
2. National Comprehensive Cancer Network, Neuroendocrine and Adrenal Tumors (Version 2.2020) 2020.

3. Pavel, M., et al., Gastroenteropancreatic neuroendocrine neoplasms: ESMO Clinical Practice Guidelines for diagnosis, treatment and follow-up. Ann Oncol, 2020. 31(7): p. 844-860.

4. Modlin, I.M., et al., Current status of gastrointestinal carcinoids. Gastroenterology, 2005. 128(6): p. 1717-51.

5. WHO classification of Tumours Editorial Board, Digestive system tumours. 5th ed. 2019: World Health Organization (WHO).

6. Longcroft-Wheaton, G. and P. Bhandari, Endoscopic resection of submucosal tumors. Expert Rev Gastroenterol Hepatol, 2015. 9(5): p. 659-69.

7. Zhang, Q., et al., Endoscopic resection of gastric submucosal tumors: A comparison of endoscopic nontunneling with tunneling resection and a systematic review. Saudi journal of gastroenterology: official journal of the Saudi Gastroenterology Association, 2017. 23(1): p. 52-59.

8. Maggard, M.A., J.B. O'Connell, and C.Y. Ko, Updated population-based review of carcinoid tumors. Ann Surg, 2004. 240(1): p. 117-22.

9. Jetmore, A.B., et al., Rectal carcinoids: the most frequent carcinoid tumor. Dis Colon Rectum, 1992. 35(8): p. 717-25.

\section{THỰC TRẠNG BÊ̂NH KHÔ MẮT TRÊN SINH VIÊN NĂM THỨ 5 ĐẠI HỌC Y DƯợC THÁI NGUYÊN VÀ MộT SỐ YẾU TỐ LIÊN QUAN}

\section{Lương Thị Hải Hà*, Đặng Đức Minh*, Vũ Quang Dũng*, Vũ Thị Kim Liên*, Nguyễn Thị Thanh Dung*, Ninh Quang Hưng*}

\section{TÓM TẮT}

Mưc tiêu: Mô tả thực trang bệnh lý khô mắt và một số yếu tố liên quan ở sinh viên năm thứ 5 trường đaii hoc $Y$ Dược Thái Nguyên. Đối tượng và phương pháp: Nghiên cứu được tiến hành trên 552 sinh viên năm thứ 5 hệ Bác sĩ đa khoa, trường đại học $Y$ Dược Thái Nguyên. Nghiên cứu mô tả cắt ngang.Kết quả: Thị lực tốt sau chỉnh kính tối ưu đạt 95,7\%, 31,9\% sinh viên có điểm OSDI ở mức khô mắt nhe và $3,0 \%$ sinh viên có điểm OSDI ở mức khô mắt trung bình, $9,7 \%$ sinh viên bị khô mắt trong đó có $72,7 \%$ khô mắt nhe và $28,3 \%$ khô mắt vừa. - Một số yếu tố liên quan đến tỷ lệ: thời gian sử dung thiết bi điên tử quá nhiều, thời gian đọc sách liên tục > 6 giờ/ngày và việc có/không tham gia các hoạt động ngoài trời. Kết luận: Khô mắt gặp trên sinh viên năm thứ 5 có tỷ lệ $9,7 \%$, thời gian sử dụng thiết bị điện tử quá nhiều, thời gian đọc sách liên tục > 6 giờ/ngày và việc

*Trường Đại học Y Dược Thái Nguyên Chịu trách nhiệm chính: Lương Thị Hải Hà Email: haihamat@gmail.com

Ngày nhận bài: 13.11.2020

Ngày phản biên khoa họ: 21.12.2020

Ngày duyệt bài: 4.01.2021 có/không tham gia các hoạt động ngoài trời là các yếu tố có liên quan đến tình trạng khô mắt trên đối tượng nghiên cứu.

Tư khóa: Thi lực, khô mắt, bề măt nhãn cầu,...

Chũ viêt tắt: OSDI (Ocular surface disease index), TBUT (Tear break up time), bề mặt nhãn cầu,

\section{SUMMARY \\ SITUATION OF DRY EYES DISEASE IN THE \\ $5^{\text {th }}$-YEAR-STUDENT IN THAI NGUYEN UNIVERSITY OF MEDICINE AND PHARMACY AND SOME RELATED FACTORS}

Objective: Describe the situation of dry eyes disease and some related factors in the $5^{\text {th }}$-yearstudent in Thai nguyen university of medicine and pharmacy. Methods: The study was conducted on 552 students. Cross-sectional descriptive study. Results: Good vision acuty after optical corection was $95,7 \%$, the students with low OSDI score was $31,9 \%$ and average OSDI score was 3,0\%, the rate of dry eyes was $9,7 \%$, inside $72,7 \%$ with low dry eyes and $28,3 \%$ with medium dry eyes. - Some related factors: time up for using electronic devices, time up for reading book more than $6 \mathrm{~h} /$ day, participate in outdoor activities. Conclusion: the rate of dry eyes in the $5^{\text {th }}$ year-student was $9,7 \%$, time up for using electronic 